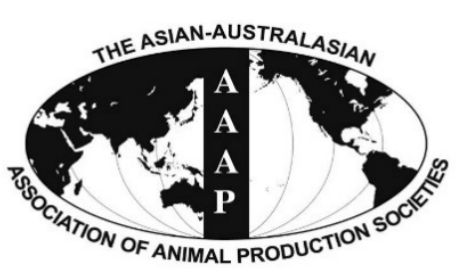

\title{
Expression and Distribution of the Guanine Nucleotide-binding Protein Subunit Alpha-s in Mice Skin Tissues and Its Association with White and Black Coat Colors
}

\author{
Zhihong Yin, Xin Zhao, Zhun Wang, Zhen Li, Rui Bai, Shanshan Yang, Min Zhao ${ }^{1}$, and Quanhai Pang* \\ College of Animal Science and Veterinary Medicine, Shanxi Agricultural University, Taigu, Shanxi 030800, China
}

\begin{abstract}
Guanine nucleotide-binding protein subunit alpha-s (Gnos) is a small subunit of the G protein-couple signaling pathway, which is involved in the formation of coat color. The expression level and distribution of Gnos were detected by quantitative real-timepolymerase chain reaction (qPCR), western blot, and immunohistochemistry to investigate the underlying mechanisms of coat color in white and black skin tissues of mice. qPCR and western blot results suggested that Gnos was expressed at significantly higher levels in black mice compared with that of white mice, and transcripts and protein possessed the same expression in both colors. Immunohistochemistry demonstrated Gnas staining in the root sheath and dermal papilla in hair follicle of mice skins. The results indicated that the Gnas gene was expressed in both white and black skin tissues, and the expression level of Gnas in the two types of color was different. Therefore, Gnas may be involved in the coat color formation in mice. (Key Words: Mice, Guanine Nucleotidebinding Protein Subunit Alpha-s, Coat Color, Hair Follicle, Skin Tissue, Melanocyte, Pigmentation)
\end{abstract}

\section{INTRODUCTION}

For mammals, coat color is not only a quality trait of a hereditary basic, but also main phenotypic trait, and economic trait, especially for sheep (Fan et al., 2013), rabbit (Jiang et al., 2002), alpaca (Bai et al., 2010; Tian et al., 2015; Yu et al., 2015), and other wool-producing animals. In mammals, melanocytes produce eumelanin (black pigment) and pheomalanin (yellow pigment) (Ito and Wakamatsu, 2003), and coat color is determined by the distribution and ratio of the two types of melanin. Melanin is formed by gene action, gene interaction, and environmental factors (Sturm et al., 2001; Ma et al., 2013). Different coat colors of mammal are formed by mutant or interaction of many genes (Van Raamsdonk et al., 2009;

\footnotetext{
* Corresponding Author: Quanhai Pang. Tel: +86-354-6285941, Fax: +86-354-6285941, E-mail: pangquanhai@126.com

1 Shaanxi Animal Health Inspection, Xi'an, Shaanxi 710000, China.

Submitted Aug. 30, 2015; Revised Nov. 18, 2015; Accepted Jan. 5, 2016
}

Dong et al., 2012; Haase et al., 2013; Yu et al., 2015). Melanocytes are distributed in the epidermis, dermis and hair follicle. In adult animals, coat color is dependent on melanin produced by melanocytes at the base of hair follicles. In studying signal transduction of hair follicle, researchers have mainly focused on the melanocortin receptor $1 /$ protein kinase A (MC1R/PKA) signaling pathways (Våge et al., 2014; Dorshorst et al., 2015), Wnt/ $\beta$ catenin signaling pathways (Enshell-Seijffersa et al., 2010), mitogen-activated protein kinase signaling pathways (Eriksson et al., 2008; Feng et al., 2014), and other signaling pathways, which are involved the growth and development stages of hair follicles and control the proliferation and differentiation of the hair follicle epithelial cells (Tian and Fan, 2006). Recently, some subunits of G protein-couple signaling pathway have been found to regulate and control coat color formation by mutation (Van Raamsdonk et al., 2004; 2009). As a result, the G proteincouple signaling pathway captures has attracted research attention.

$\mathrm{G}$ protein-coupled signaling pathways consist of seven

Copyright $@ 2016$ by Asian-Australasian Journal of Animal Sciences This is an open-access article distributed under the terms of the Creative Commons Attribution Non-Commercial License (http://creativecommons.org/licenses/by-nc/3.0/), which permits unrestricted non-commercial use, distribution, and reproduction in any medium, provided the original work is properly cited. 
transmembrane receptors associated with a heterotrimeric $\mathrm{G}$ protein. Heterotrimeric G protein has high molecular weight, and is a signal transduction molecule, which are regulated by guanine nucleotide (Oldham and Hamm, 2008). Heterotrimeric $\mathrm{G}$ proteins contain three subunits, i.e., alpha, beta, and gamma. The four classes of alpha subunits,

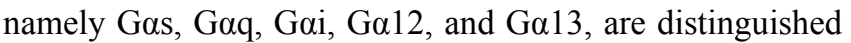
by the type of downstream effectors (Oldham and Hamm, 2008; Van Raamsdonk et al., 2009). The melanocortin and endothelin signaling pathway are two $G$ protein-coupled pathways. Gas is involved in the melanocortin signaling pathway and produces eumelanin in melanocytes (Van Raamsdonk et al., 2009). Guanine nucleotide-binding protein subunit alpha-s (Gnos) is closely related to the alpha subunits of the s class. We speculate that Gnos is associated with coat color formation. We selected white and black skin of 21 day-old mice and analyzed the Gnos expression level and distribution in mice skins tissues to explore the relation between Gnas and pigmentation in $G$ protein-couple signaling pathway.

\section{MATERIALS AND MEDTHODS}

\section{Animals and tissue collection}

Skin samples were collected and mice were maintained in accordance with the International Guiding Principles for Biomedical Research Involving Animals (http://www. cioms.ch/frame1985textsofguidelines.html). Six healthy 21day-old white and black female mice (three mice per color) were selected from Peking University Health Science Center (Beijing, China) for sample collection (Figure 1). Hair at the back of the mice was carefully trimmed using fine dissecting scissors (Tian et al., 2012) to avoid bleeding. Each piece of skin $(8 \mathrm{~mm} \times 8 \mathrm{~mm})$ from the back was collected through punch skin biopsy under local anesthesia and immediately placed in liquid nitrogen for further experiments. Six additional white and black skin tissues (three mice per color) were fixed in 4\% paraformaldehyde and analyzed through immunohistochemistry.

Reverse transcription and quantitative real-timepolymerase chain reaction assay

Total RNA was extracted from white and black skin tissues by using RNAiso Plus (TaKaRa, Dalian, China). RNA integrity was evaluated on the basis of OD260/OD280, which was between 1.8 and 2.0 for the next experiment.
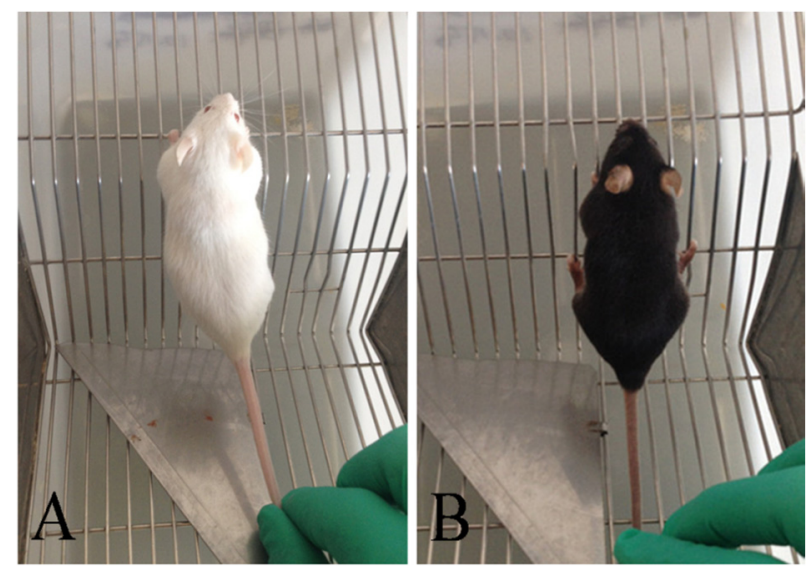

Figure 1. The picture of the two colors variant mice. A: The white mouse. B: The black mouse.

Subsequently, $1 \mu \mathrm{g}$ of DNase-treated RNA of each sample was transcripted into cDNA by using $5 \times$ PrimeScript RT Master Mix (Perfect Real Time) (TaKaRa, China) in accordance with the manufacturer's instructions.

Gnos gene primers were designed on the basis of a specific sequence by using an online Primer 3 program (Table 1), and $\beta$-actin was used as internal control (primers are listed in Table 1). Quantitative real-time-polymerase chain reaction (qPCR) was performed using a SYBR Premix Ex Taq II (Tli RNaseH Plus) (TaKaRa, China) implemented in MXPro-3000P (Stratagene, La Jolla, CA, USA). The $25 \mu \mathrm{L}$ PCR reaction mixtures contained $12.5 \mu \mathrm{L}$ of SYBR Premix Ex Taq II, $0.5 \mu \mathrm{L}$ of forward primer (10 $\mathrm{pM}), 0.5 \mu \mathrm{L}$ of reverse primer $(10 \mathrm{pM}), 0.5 \mu \mathrm{L}$ of $\mathrm{ROX}$ reference dye, $2.0 \mu \mathrm{L}$ of template, and $9 \mu \mathrm{L}$ of water. The PCR conditions were as follows: $95^{\circ} \mathrm{C}$ held for $30 \mathrm{~s}$, followed by 40 cycles of $95^{\circ} \mathrm{C}$ for $5 \mathrm{~s}, 60^{\circ} \mathrm{C}$ for $34 \mathrm{~s}$, and $72^{\circ} \mathrm{C}$ for $15 \mathrm{~s}$. Gnas mRNA abundance was quantified using the comparative threshold cycle (CT) method established by (Livak and Schmittgen, 2001).

\section{Western blot analysis of Gnos}

Total protein was extracted from skin tissues by using a tissue protein extraction kit (Boster, Wuhan, China), and protein concentrations were measured by using bicinchoninic acid protein assay kit (Boster, China) in accordance with the manufacturers' instructions. Protein samples $(300 \mu \mathrm{g})$ were subjected to $8 \%$ sodium dodecyl sulfate-polyacrylamide gel electrophoresis and transferred onto Immobilon- $\mathrm{P}^{\mathrm{SQ}}$ polyvinylidene difluoride transfer

Table 1. Sequences of primer and PCR amplification of target genes and house-keeping

\begin{tabular}{llccc}
\hline Gene & \multicolumn{1}{c}{ Primer sequences $\left(5^{\prime}-3^{\prime}\right)$} & Product $(\mathrm{bp})$ & Tm $\left({ }^{\circ} \mathrm{C}\right)$ & Accession No. \\
\hline Gnos & F: TGCTTCGGTCTATCCGAGTGT & 180 & 59.8 & NM_201618 \\
& R:GTCCATCTTCTCCTCCTCCAGTT & & \\
$\beta$-actin & F: TTGCTGACAGGATGCAGAAG & 141 & 60 & NM_007393.3 \\
& R: ACATCTGCTGGAAGGTGGAC & & \\
\hline
\end{tabular}

PCR, polymerase chain reaction; F, sense primers; R, antisense primers. 
membrane (Gnos, $0.45 \mu \mathrm{m}$; $\beta$-actin, $0.22 \mu \mathrm{m}$; Boster, China). The membrane was blocked with $5 \%$ non-fat milk (Boster, China) in a mixture of TBST (Tris-buffered saline and Tween 20; $150 \mathrm{mM} \mathrm{NaCl}, 10 \mathrm{mM}$ Tris, $\mathrm{pH}=7.0$, $0.05 \%$ Tween-20) for $1.5 \mathrm{~h}$ at room temperature. The membrane was incubated at $4{ }^{\circ} \mathrm{C}$ overnight in polyclonal rabbit anti-G protein alpha $\mathrm{S}$ antibody $(1: 1,500$ [vol/vol] in TBST; Abcam, Cambridge, UK). Goat anti-rabbit IgG $(\gamma-$ chain specific) antibody (1:5,000 [vol/vol]; Boster, China) was incubated with the membrane for $1 \mathrm{~h}$ at $37^{\circ} \mathrm{C}$. The protein bands were visualized using a super ECL Chemiluminescence plus kit (Boster, China). Band intensities were scanned and visualized using Image Lab software with a Bio-Rad system (Bio-Rad, Hercules, CA, USA). Mice anti- $\beta$-actin (mice $\operatorname{IgG})(1: 2,000$ [vol/vol]; Boster, China) was used as a loading control. The horseradish peroxidase-conjugated goat anti-mice IgG $(\gamma-$ chain specific) at a dilution of $(1: 5,000$ [vol/vol]; Boster, China) was used as secondary antibody, the other steps were carried out as described above. Experiments were performed in triplicates.

\section{Immunohistochemical analysis}

White and black skin tissues were fixed in $4 \%$ paraformaldehyde, and then the paraffinized skin tissue sections $(8 \mu \mathrm{m})$ were deparaffinized. The sections were dehydrated using graded ethanol $(100 \%, 95 \%, 90 \%, 85 \%$, $80 \%$, and $70 \%$ ). After washing for three times (5 min each) with phosphate-buffered saline (PBS, $\mathrm{pH}=7.4)$, the sections were incubated in $3 \% \mathrm{H}_{2} \mathrm{O}_{2}$ (Boster, China) for 10 min to eliminate endogenous peroxidase activity. After washing for three times ( 5 min each) with PBS, the sections were incubated in 5\% bovine serum albumin (Boster, China) for $20 \mathrm{~min}$ at room temperature to block non-specific binding, then incubated with polyclonal rabbit anti-Gnas (1:200 [vol/vol] in PBS; Abcam, USA) at $4^{\circ} \mathrm{C}$, overnight. Then, after washing for three times ( 5 min each) with PBS, the sections were incubated in biotin conjugated goat antirabbit IgG (Boster, China) at $37^{\circ} \mathrm{C}$ for $20 \mathrm{~min}$. After washing for three times ( 5 min each) with PBS, the sections were incubated in horseradish reddish peroxidase (HRP; Boster, China) at $37^{\circ} \mathrm{C}$ for $20 \mathrm{~min}$. After washing for three times (5 min each) in PBS, immunoreactivity was visualized by incubating sections in the presence of 3,3 "diaminobenzidine (DAB; Boster, China) substrate at room temperature for $3 \mathrm{~min}$. The sections were counterstained with hematoxylin, and then dehydrated, and clear sealed with neutral balsam. Positive results were indicated by brown appearance. PBS was used as negative control instead of polyclonal rabbit anti-Gnas (Tian et al., 2015).

\section{Statistical analysis}

Data were analyzed using SPSS statistical software 17.0
(SPSS Inc., East Lansing, MI, USA), expressed as mean \pm standard deviation, and analyzed via Student's $t$-test. A one-way analysis of variance testing was used to determine statistical differences between data.

\section{RESULTS AND DISCUSSION}

\section{Expression of Gnos in white and black mice skins}

Coat color is particularly important in mammals because color affects fiber value (Fan et al., 2013; Li et al., 2014). Coat color depends on the amounts and types of melanin produced by melanocytes in the hair follicles (Ito and Wakamatsu, 2008). Previous research showed that the quantity and the ratio of eumelanin to pheomelanin are the major determinants of coat color; however, coat color is white when hair follicles have few melanocytes (Ito and Wakamatsu, 2003). The melanocortin pathway signals through Gas to produce pigment by melanocytes in hair follicles (García-Borrón et al., 2005; Van Raamsdonk et al., 2009). MC1R is activated by alpha-melanin stimulating hormone in melanocytes, and then stimulates the Gas to produce cAMP in melanocytes by the function of adenylate cyclase, resulting in eumelanin production (Robbins et al., 1993).

Accordingly, in order to understanding the action of Gnas on regulating melanin synthesis, we detected the expression of Gnos mRNA and protein by qPCR and western blot in different skin colors. The expression levels of Gnos mRNA in mice skins with different coat colors were shown in Figure 2. The relative expression level of Gnas transcripts in black skin was 3.94 times higher than that in white skin. Furthermore, the protein level of Gnas was analyzed by western blot. Figure 3 showed that the Gnas protein level in the skin of black mice was significantly increased by as much as 2.85 -fold that in white

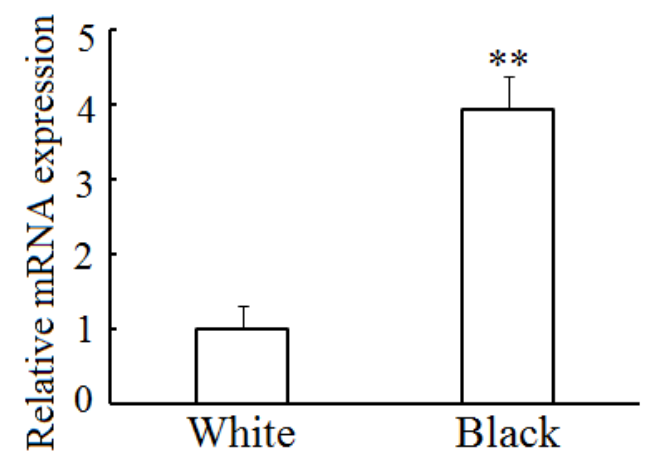

Figure 2. Relative expression levels of Gnas mRNA in skin samples collected from white and black mice. Relative mRNA expression of Gnas was normalized relative to abundance of $\beta$ actin. Bars in panels represent the mean \pm standard deviation $(\mathrm{n}=$ $3),{ }^{* *} \mathrm{p}<0.01$. Gn $\alpha$ s, guanine nucleotide-binding protein subunit alpha-s. 

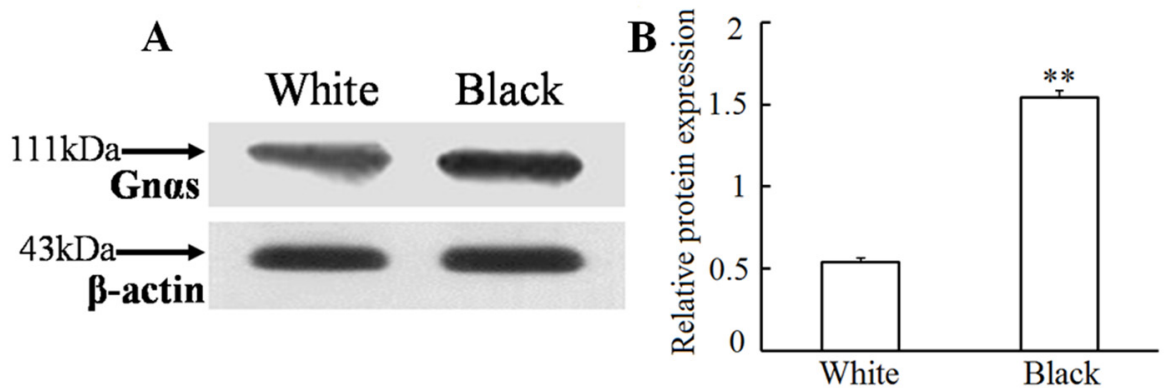

Figure 3. Expression of Gnas protein analyzed by western blot in white and black mice skins. (A) Western blot results of Gnas in white and black mice skins. (B) Gnas protein expression in white and black mice skins. Bars in panel represent mean \pm standard deviation ( $\mathrm{n}=$ $3), * * \mathrm{p}<0.01$. Gnas, guanine nucleotide-binding protein subunit alpha-s.

mice skin. The Gnas protein level was consistent with the mRNA expression level in the two coat colors, which suggested that Gnas expression in the skin of black mice was higher than that in white mice. The significant expression of Gnas in black coat color might be due to the effect of Gnas on eumelanin synthesis by MC1R signaling in the melanocortin pathway. Many studies have indicated that high MC1R signaling results in eumelanin production, and thus formation of dark coats in mice (Lai et al., 2007; Pérez-Oliva et al., 2009; Våge et al., 2014). We suspect that a number of eumelanin was produced by melanocytes through Gnas signaling in hair follicles of black mice; on the contrary, fewer melanocytes produced melanin in hair follicles of white mice. The activity of eumelanin in black mice skins was speculated to be stronger than that in white mice. Moreover, previous research demonstrated that the amount of MC1R decreases by inhibiting, the expression of Gas (Pérez-Oliva et al., 2009), which implies that Gas expression is positively correlated with MC1R expression. Based on our experimental results, we conjectured that adequate Gnos was stimulated by MC1R in mice with black coat color, thereby producing eumelanin by melanocytes in hair follicles. Conversely, a certain amount of eumelanin is not synthesized in skin of white mice.

\section{Distribution of Gnos in white and black mice skins}

To study the role of Gnas on the formation of coat color further, we detected the location of Gnas in hair follicles by immunohistochemistry. As shown in Figure 4, Gnas protein was detected in hair follicles of both skin colors. No positive expression was detected in the negative controls (Figure 4C and 4D). As we expected, Gnas protein was mainly expressed in the root sheath and dermal papilla of hair follicles (Figure 4A and 4B). Animal coat color depends on the pigment-producing melanocytes located in the hair follicle matrix (Ohta et al., 2013), and dermal papilla (Millar et al., 1995; Slominski et al., 2005). Melanoblasts present in root sheath differentiate into activated melanocytes in dermal papilla of hair follicles. Melanoblasts are precursors of melanocytes and they are inactivated in root sheath. Melanocytes are activated in dermal papilla, and they produced pigments. Therefore, we hypothesize that Gnas is possibly involved in hair pigment production.

\section{CONCLUSION}

Black mice skin exhibited significantly higher Gnas mRNA and protein expression levels than white mice skin. Gnos was distributed in the root sheath and dermal papilla of hair follicles. Our results provide basic evidence supporting that Gnas may be involved in coat color formation.

\section{CONFLICT OF INTEREST}

We certify that there is no conflict of interest with any

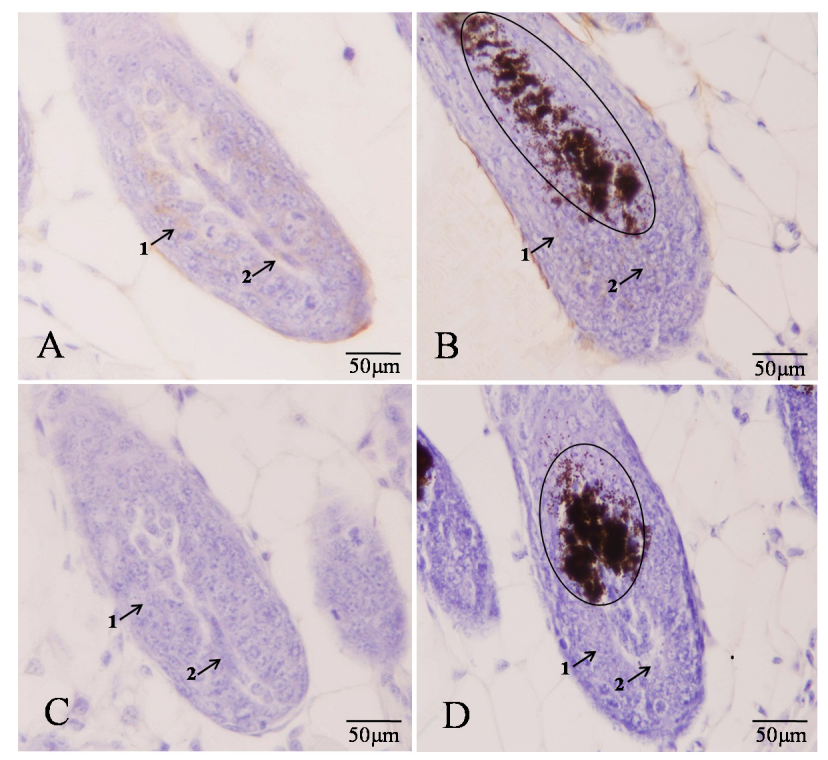

Figure 4. Immunohistochemical analysis of the location of Gnas expression in white and black mice. (A), (B): Positive expression of Gnas in white and black mice skins; (C), (D): Negative control of Gnas in white and black mice skins. 1: root sheath; 2: dermal papilla. The black arrow shows melanin grain. Gnas, guanine nucleotide-binding protein subunit alpha-s. 
financial organization regarding the material discussed in the manuscript.

\section{ACKNOWLEDGMENTS}

This study was supported by National Natural Science Foundation of China (No. 30972223; No. 31272628) and Graduate Innovation Project of Shanxi Province (Grant No. 2015BY30).

\section{REFERENCES}

Bai, R., A. Sen, Z. H. Yu, G. Yang, H. D. Wang, R. W. Fan, L. H. Lv, K-B. Lee, G. W. Smith, and C. S. Dong. 2010. Validation of methods for isolation and culture of alpaca melanocytes: A novel tool for in vitro studies of mechanisms controlling coat color. Asian Australas. J. Anim. Sci. 23:430-436.

Dong, C. S., H. D. Wang, L. L. Xue, Y. J. Dong, L. Yang, R. W. Fan, X. J. Yu, X. Tian, S. H. Ma, and G. W. Smith. 2012. Coat color determination by miR-137 mediated down-regulation of microphthalmia-associated transcription factor in a mouse model. RNA 18:1679-1686.

Dorshorst, B., C. Henegar, X. Liao, M. Sällman Almén, C. J. Rubin, S. Ito, K. Wakamatsu, P. Stothard, B. Van Doormaal, G. Plastow, G. S. Barsh, and L. Andersson. 2015. Dominant red coat color in holstein cattle is associated with a missense mutation in the coatomer protein complex, subunit alpha (COPA) gene. PLoS One 10:e0128969.

Enshell-Seijffers, D., C. Lindon, E. Wu, M. M. Taketo, and B. A. Morgan. 2010. Beta-catenin activity in the dermal papilla of the hair follicle regulates pigment-type switching. Proc. Natl. Acad. Sci. USA. 107:21564-21569.

Eriksson, T. L., S. P. Svensson, I. Lundström, K. Persson, T. P. M. Andersson, and R. G. G. Andersson. 2008. Panax ginseng induces anterograde transport of pigment organelles in Xenopus melanophores. J. Ethnopharmacol. 119:17-23.

Fan, R. W., J. S. Xie, J. M. Bai, H. D. Wang, X. Tian, R. Bai, X. Y. Jia, L. Yang, Y. F. Song, M. Herrid, W. J. Gao, X. Y. He, J. B. Yao, G. W. Smith, and C. S. Dong. 2013. Skin transcriptome profiles associated with coat color in sheep. BMC Genomics 14:389.

Feng, H., Y. Sun, and Q. Wang. 2014. Downregulation of cKit/MITF-M in graying hair of juvenile poliosis. Acta Derm. Venereol. 94:484-485.

García-Borrón, J. C., B. L. Sánchez-Laorden, and C. JiménezCervantes. 2005. Melanocortin-1 receptor structure and functional regulation. Pigment Cell Res. 18:393-410.

Haase, B., H. Signer-Hasler, M. M. Binns, G. Obexer-Ruff, R. Hauswirth, R. R. Bellone, D. Burger, S. Rieder, C. M. Wade, and T. Leeb. 2013. Accumulating mutations in series of haplotypes at the KIT and MITF loci are major determinants of white markings in Franches-Montagnes horses. PLoS One 8:e75071.

Ito, S. and K. Wakamatsu. 2003. Quantitative analysis of eumelanin and pheomelanin in humans, mice, and other animals: A comparative review. Pigment Cell Res. 16:523-531.

Ito, S. and K. Wakamatsu. 2008. Chemistry of mixed melanogenesis-pivotal roles of dopaquinone. Photochem.
Photobiol. 84:582-592.

Jiang, Y. L., X. Z. Fan, Z. X. Lu, H. Tang, J. Q. Xu, and L. X. Du. 2002. Detection of $881^{\mathrm{A}} \rightarrow 881^{\mathrm{G}}$ mutation in tyrosinase gene and associations with the black ear coat color in rabbits. Asian Australas J. Anim. Sci. 15:1395-1397.

Lai, F. J., J. Ren, H. S. Ai, N. S. Ding, J. W. Ma, D. Q. Zeng, C. Y. Chen, Y. M. Guo, and L. S. Huang. 2007. Chinese white Rongchang pig does not have the dominant white allele of KIT but has the dominant black allele of MC1R. J. Hered. 98:84-87.

Li, M. H., T. Tiirikka, and J. Kantanen. 2014. A genome-wide scan study identifies a single nucleotide substitution in ASIP associated with white versus non-white coat-colour variation in sheep (Ovis aries). Heredity 112:122-131.

Livak, K. J. and T. D. Schmittgen. 2001. Analysis of relative gene expression data using real-time quantitative PCR and the $2^{-\Delta \Delta C}$ T method. Methods 25:402-408.

Ma, S. H., L. L. Xue, G. Xu, Y. Q. Hou, J. J. Geng, J. Cao, X. Y. He, H. D. Wang, and C. S. Dong. 2013. The influences of over-expressing miR-137 on TYRP-1 and TYRP-2 in melanocytes. China Agric. Sci. 46:3452-3459.

Millar, S. E., M. W. Miller, M. E. Stevens, and G. S. Barsh. 1995. Expression and transgenic studies of the mouse agouti gene provide insight into the mechanisms by which mammalian coat color patterns are generated. Development 121:3223-3232.

Ohta, S., Y. Imaizumi, Y. Okada, W. Akamatsu, R. Kuwahara, M. Ohyama, M. Amagai, Y. Matsuzake, S. Yamanaka, H. Okano, and Y. Kawakami. 2013. Generation of human melanocytes from induced pluripotent stem cells. PLoS ONE 6:e16182.

Oldham, W. M. and H. E. Hamm. 2008. Heterotrimeric G protein activation by G-protein-coupled receptors. Nat. Rev. Mol. Cell Biol. 9:60-71.

Pérez-Oliva, A. B., C. Olivares, C. Jiménez-Cervantes, and J. C. García-Borrón. 2009. Mahogunin ring finger-1 (MGRN1) E3 ubiquitin ligase inhibits signaling from melanocortin receptor by competition with $G$ alphas. J. Biol. Chem. 284:3171431725.

Robbins, L. S., J. H. Nadeau, K. R. Johnson, M. A. Kelly, L. Roselli-Rehfuss, E. Baack, K. G. Mountjoy, and R. D. Cone. 1993. Pigmentation phenotypes of variant extension locus alleles result from point mutations that alter MSH receptor function. Cell 72:827-834.

Slominski, A., J. Wortsman, P. M. Plonka, K. U. Schallreuter, R. Paus, and D. J. Tobin. 2005. Hair follicle pigmentation. J. Invest. Dermatol. 124:13-21.

Sturm, R. A., R. D. Teasdale, and N. F. Box. 2001. Human pigmentation genes: identification, structure and consequences of polymorphic variation. Gene 277:49-62.

Tian, T. and W. X. Fan. 2006. Hair follicles signal transduction. Int J. Derm. Venereol. 32:238-240.

Tian, X., J. B. Jiang, R. W. Fan, H. D. Wang, X. L. Meng, X. Y. He, J. P. He, H. Q. Li, J. J. Geng, X. J. Yu, Y. F. Song, D. L. Zhang, J. B. Yao, G. W. Smith, and C. S. Dong. 2012. Identification and characterization of microRNAs in white and brown alpaca skin. BMC Genomics 13:555.

Tian, X., X. L. Meng, L. Y. Wang, Y. F. Song, D. L. Zhang, Y. K. Ji, X. J. Li, and C. S. Dong. 2015. Molecular cloning, mRNA expression and tissue distribution analysis of Slc7all gene in alpaca (Lama paco) skins associated with different coat colours. Gene 555:88-94 
Våge, D. I., M. Nieminen, D. G. Anderson, and K. H. Røed. 2014. Van Raamsdonk, C. D., K. R. Fitch, H. Fuchs, M. H. de Angelis, Two missense mutations in melanocortin 1 receptor $(M C 1 R)$ are strongly associated with dark ventral coat color in reindeer (Rangifer tarandus). Anim. Genet. 45:750-753.

Van Raamsdonk, C. D., G. S. Barsh, K. Wakamatsu, and S. Ito. 2009. Independent regulation of hair and skin color by two $G$ protein-coupled pathways. Pigment Cell Melanoma Res. 22:819-826. and G. S Barsh. 2004. Effects of G-protein mutations on skin color. Nat. Genet. 36:961-968.

Yu, X. J., X. Y. He, J. B. Jiang, J. P. He, R. W. Fan, H. D. Wang, J. J. Geng, and C. S. Dong. 2015. Expression and tissue distribution of hepatocyte growth factor (HGF) and its receptor (c-Met) in alpacas (Vicugna pacos) skins associated with white and brown coat colors. Acta Histochem. 117:624-628. 